\title{
The Study of Anatomical Variations of Lateral Cord of Brachial Plexus - A Case Report
}

\author{
Mahesh Kumar* and Moh. Arshil Azeem
}

Department of Anatomy, SHKM GMC Nalhar, (Nuh), Haryana, India

*Corresponding author

\section{A B S T R A C T}

Keywords

Anatomical variations, Lateral cord

Article Info

Accepted:

12 March 2018

Available Online:

10 April 2018
Anatomical variations of brachial plexus have previously been described by various authors. But in this study more types of variations were found. The coracobrachialis muscle was innervated by nerve to coracobrachialis, a branch arising from lateral cord. The musculocutaneous nerve was not piercing the coracobrachialis. The median nerve was formed at the junction of upper one-third and lower two-third of arm by joining of lateral and medial roots from the lateral and medial cord of brachial plexus, instead in the axilla. These anatomical variations were seen on the left side of upper limb.

\section{Introduction}

Anomalies related to the formation, relations and distribution of brachial plexus cords is fairly common (Abhaya et al., 2003). Lateral cord is destined to supply the flexor compartment of the upper limb and the pectoral region. It gives off lateral pectoral nerve, musculocutaneous nerve and lateral root of median nerve. Lateral pectoral nerve supplies pectoralis major. Musculocutaneous nerve supplies coracobrachialis, biceps brachii and brachialis. Finally it pierces the deep fascia at the level of elbow to continue as lateral cutaneous nerve of forarm (Ajay, 2010). Variations of brachial plexus occurs in the formation of trunks, divisions and cords; in the origin and /or combination of branches; and in the relationship to the axillary artery and scalene muscles, however the make-up of the terminal branches (components of the nerves is unchanged (Moore and Dalley). The knowledge on variations in the course and branching of the brachial plexus assumes importance while neurotisation of brachial plexus lesions, shoulder arthroscopy through anterior gleno-humeral portal and shoulderreconstructive surgeries are performed (Chitra, 2007; Gupta et al., 2011). Normal functioning of the limbs may not be altered by these variations, but it is important to remember these variations during performance of surgical and anaesthesiological procedures (Harris and Heymann, 1904). Multiple variations in association with lateral cord piercing coracobrachialis are rare. These 
variations if inappropriately compressed could lead to distal neuropathy (Suma et al., 2016). Coracobrachialis is often used in the flap surgeries after mastectomy. Following mastectomy, the deformities in the infraclavicular region and the axilla are filled using the coracobrachialis flap. For obtaining the coracobrachialis flap, anatomical knowledge and its morphological variants are crucial to the surgeon. During the procedure, structures piercing coracobrachialis are prone to injury particularly if there is an unnoticed anatomical variation (Butz et al., 2014)

\section{Observations}

During routine dissection of about 45 year old embalmed male cadaver in Department of Anatomy, a rare unilateral variation of the lateral cord of brachial plexus was observed. In left upper limb, the axilla and arm were dissected. The cords and the branches of cords were observed. The coracobrachialis muscle was innervated by nerve to coracobrachialis, a branch arise from lateral cord. Musculocutaneous nerve was not piercing the coracobrachialis muscle.

The median nerve was formed in the anterior and medial aspect of brachial artery by joining of lateral and medial root lower down, at the junction of the upper one-third and lower twothird of arm, instead of axilla.

\section{Results and Discussion}

Unilateral brachial plexus anomalies were demonstrated in 4 of 71 cadavers by (Sarsilmaz et al., 1993). During gross anatomy dissection of 60 embalmed cadavers by Gumusalan et al., the coracobrachialis muscle was found to be innervated by a nerve branch arising from the lateral root of the median nerve but not from the musculocutaneous nerve nor from the lateral cord of brachial plexus.

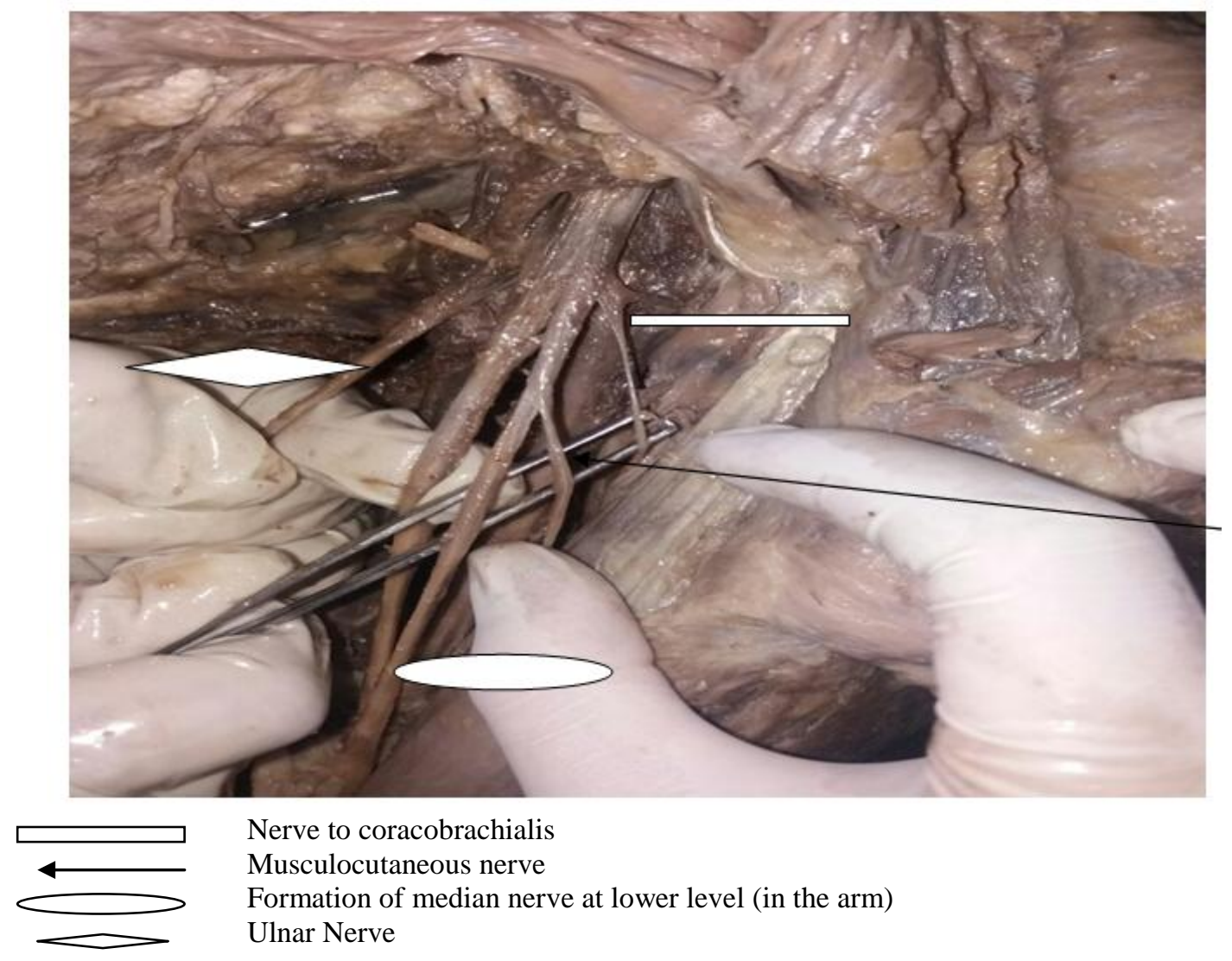


Furthermore, the musculocutaneous nerve was found not to pierce the coracobrachialis muscle and to course-downwards medial to it (Gumusalan et al., 1998). In our case, in contrast, the coracobrachialis was innervated by a branch from lateral cord and musculocutaneous nerve was not found to pierce the coracobrachialis. Ilkan Tatar et al., (2004) during dissection found that coracobrachialis was not innervated by musculocutaneous nerve. Instead by a branch of lateral root of median nerve but in our case, coracobrachialis is innervated by direct branch from lateral cord. Bala et al., (2014) during dissection on 30 human cadevers found that median nerve was formed in anterior and medial aspect of the brachial artery by joining of lateral and medial roots from the lateral and medial cords of brachial plexus lower down, at the junction of the upper one - third and lower one-third arm instead of being in the axilla (same in our case) and similar findings were also reported earlier (Sheetal et al., 2012; Charushila et al., 2015; Kumar and Teja, 2016; Devi et al., 2011; James et al., 2014). In present study, musculocutaneous nerve was not piercing the coracobrachialis, which is similar to the findings of Kumar N, Jamuna $M(n=50)$, Grish V Patil, Kisore CK ( $=40)$, Shivi Goel. Though a lots of variations was seen in the branching pattern of brachial plexus in previous studies but our study showed a few additional one.

Anatomical variations reported in the present study are of great interest to neurosurgeons and researchers, while they carry out surgical procedures.

\section{References}

Abhaya A, Khanna J, Prakash R. Variation of lateral cord of the brachial plexus piercing coracobrachialis muscle. J Anat Soc India 2003; 52(2):168-70.
Ajay RN. Why medial cord variations seen infrequently? Eur J Anat 2010; 14:5965.

Bala A, Sinha P, Tamag BT, Sarda RK. Anatomical variation: Median nerve formation- A case vignette. J Clin Diag Res 2014; 8(6): AD03-AD04.

Butz JJ, Shiwlochan DG, Brown KC, Prasad AM, Murlimanju BV, Viswanath S. Bilateral variations of brachial plexus involving the median nerve and lateral cord: An anatomical case study with clinical implications. AMJ 2014; 75:227-31.

Charushila et al., A cadaveric study on anatomical variations of median nerve formation: Embryological and clinical correlations; Int J Sci Res, 2015; 4(4):288-90.

Chitra, R., Various types of intercommunication between musculocutaneous and median nerves: An analytical study. Annals of Indians academy of neurology. 2007; 10(2):100-4.

Devi S, Udhaya K, Seshayan S. A study on the variations of median nerve formation in South Indian Population. Int J Anat Sci. 2011; 2(1):7-10.

Goel et al., Multiple unilateral variations in medial and lateral cord of brachial plexus and their branches. Anat Cell Biol. 2014; 77-80

Gumusalan Y, Yazar E, Ozan H. 1998. Variant innervations of the coracobrachialis muscle and unusal course of the musculocutaneous nerve in man. Anat Sci International, 73: 26972.

Gupta, C., AS D'Souza, P Shetty, P Vidya, Arunashri A. Morphological study to note the anatomical variations in the branching pattern of the lateral cord of the brachial plexus. J Morphological Science. 2011; 28(3):61-4. 
Harris, W., and HO Heymann. The true form of brachial plexus. J Anat and Physio. 1904; 38:399-422. (PMC free article) (PubMed)

Ilkan Tatar, Recep Brohi, Fikret Sen, Alikemal Tonak, Hamdi Celik. Innervation of the coracobrachialis muscle by a branch from the lateral root of the median nerve. Folia Morphol. 2004; 63:4.

James et al., Bilateral variations of brachial plexus involving the median nerve and lateral cord: an anatomical case study with clinical implications. Aus Med J. 2014; 7(5):227-231.

Jamuna M, Amudha G. A cadaveric study on the anatomical variations of the musculocutaneous nerve in the infraclavicular part of the brachial plexus. J Clinical Diag Res. 2011; 5(6):1144-47.

Kumar PA, and Teja ER. Anatomical variations in origin, number, course and relations of the roots of median nerve and the low level formation of median nerve trunk. Int J Sci Stud. 2016; 4(8):78-82.

Moore KL, and Dalley AF, Clinically oriented anatomy. $4^{\text {th }}$ ed. Philadelphia,
Lippincott, Williams and Wilkins. 199; 714-15.

Naveen KB, Sirisha V, Udaya KP, Kalpana T. The formation of lateral cord of brachial plexus and its branches-A cadaveric study. Int J Anat Res. 2018; 6(1.1):4836-39.

Patil GV, Kumar S. Musculocutaneous nerve not piercing the coracobrachialis muscle and also having communication with median nerve- A case Report. 2014; 3(7):26-27.

Sarsilmaz M, Sendemir E, Celik HH, Gumusalan Y, Simsek C. Some variations of the brachial plexus in man. Turk J Med Res, 1993; 11:161-65.

Sheetal et al., A study of the formation and branching pattern of brachial plexus and its variations in adult human cadavers of North Karnataka; J Sci Soc, 2012; 39:2.

Suma HY, Ariyanachi K, Anitha Nancy T. Multiple variations of lateral cord of brachialis plexus and its branches in the arm. Int J Anat and Res 2016, Vol 4(2):2498-01.

Thakur KC, Jethani SL, Parsad V. Non piercing variation of musculocutaneous nerve. J Evol Med and Dent Sci. 2015; 4(90):15515-17.

\section{How to cite this article:}

Mahesh Kumar and Moh. Arshil Azeem. 2018. The Study of Anatomical Variations of Lateral Cord of Brachial Plexus - A Case Report. Int.J.Curr.Microbiol.App.Sci. 7(04): 1523-1526. doi: https://doi.org/10.20546/ijcmas.2018.704.171 